\title{
Evaluation Of Anti-Hyperlipidemic Potentials Of Aqueous Fruit Pulp Extract Of Adensonia Digitata In Experimental Rats
}

\author{
Alhassan, A.J. \\ Muhammad I.U. \\ Jarumi, I.K. \\ Wudil A.M. \\ Department of Biochemistry, Faculty of Basic Science, \\ Bayero University, Kano, Nigeria
}

doi: 10.19044/esj.2016.v12n12p298 URL:http://dx.doi.org/10.19044/esj.2016.v12n12p298

\section{Abstract}

Introduction: Hyperlipidemia is a modifiable risk factor of an important killer disease “cardiovascular diseases”, research work exploring anti- hyperlipidemic activity of local plant is timely gesture. Aim: To investigate anti-hyperlipidemic ability of aqueous fruit pulp extract of Adensonia digitata in experimental rats. Methodology: Hyperlipidemia was induced in rats via feeding on high lipid diet (HLD) for 3 weeks. A total of 42 rats used, were divided into seven groups (GI - GVII) of six rats each. GI served as normal control, GII were normal rats administered with only the extract and GIII serves as hyperlipidemic control group. While GIV, GV and GVI were hyperlipidemic group administered with the extract at a dose of $1.25 \mathrm{~g} / \mathrm{kg}, 2.5 \mathrm{~g} / \mathrm{kg}$ and $3.75 \mathrm{~g} / \mathrm{kg}$ body weight respectively and GVII were hyperlipidemic given standard hyperlipidemic drug (atorvastatin), the hyperlipidemic rats were on high cholesterol diet throughout the study period. At the end of the first week of extract administration, three animals from each group were randomly selected and sacrificed. At the end of the second week, the remaining three animals from each group were also sacrificed and serum was collected for analysis of serum lipid profile (Total Cholesterol, LDL-Cholesterol, HDL-Cholesterol and Triglyceride). Results: Significant decrease $(\mathrm{p}<0.05)$ in the serum TC, TG, LDL-C, and a significant increase in the HDL-C levels was observed with $1.25 \mathrm{~g} / \mathrm{kg}$, $2.50 \mathrm{~g} / \mathrm{kg}$ and $3.75 \mathrm{~g} / \mathrm{kg}$ in group IV, V and VI, and group VII treated with Atorvastatin when to compared with the hyperlipidemic control both in the first and second week of treatment. Conclusion: The study demonstrated that $A$. digitata aqueous fruit pulp extract possesses anti-hyperlipidemic 
property. The effects may be associated with the phytochemical content of the plant pulp. Further studies on the plant may focus on identification, isolation of active component(s) aimed at formulating anti-hyperlipidemic drugs from natural source.

Keyword: Adensonia digitata, High fat diet, Hyperlipidemia, lipid profile.

\section{Introduction}

Hyperlipidaemia or hyperlipoproteinemia involves abnormally elevated levels of any or all lipids fraction in the blood. It is the most common form of dyslipidaemias (Mathers and Loncar, 2006). The abnormalities are common in the general population, and are regarded as modifiable risk factors for cardiovascular diseases (CVDs) due to their influence on atherosclerosis (Torelli and Ryan, 2005). Atherosclerosis is a syndrome affecting arterial blood vessels due to a chronic inflammatory response of white blood cells in the walls of arteries. This is promoted by low-density lipoproteins, cholesterol and triglycerides without adequate removal of fats and cholesterol from the macrophages by functional highdensity lipoproteins (HDL). It is commonly referred to as a hardening or furring of the arteries, caused by the formation of multiple atheromatous plaques within the arteries (Ross et al., 1999). In addition, some forms may predispose to acute pancreatitis. Most cardiovascular diseases can be prevented by addressing risk factors such as tobacco use, alcohol intake, unhealthy diet and obesity, physical inactivity, high blood pressure, diabetes and raised blood lipids (Thompson, 2004).

Adansonia digitata, commonly known as the baobab, belongs to the family Malvaceae and is the most widespread of the Adansonia species in the African continent, found mostly in hot, dry savannah of sub-Saharan Africa. It is called "kukah" by many ethnic groups in Nigeria (Aliyu. 2006). The baobab has been used extensively since ancient times in traditional medicine. Baobab bark is mainly used for its medicinal properties and for its fibres (Sidibe and William, 2002). The alkaloid 'adansonin' in the bark is thought to be the active principle for treatment of malaria and other fevers, as a substitute for quinine. Several plant parts have interesting anti-oxidant, antimicobial and anti-inflammatory properties. The pulp is commonly used among Hausa - Fulani in preparing plant made local yoghurt or as additive to traditional yoghurt offered for sale by Fulani women. The hypothesis is that feeding on high lipid diet induces hyperlipidemia and or dyslipidemia, and simultaneous feeding of the hyperlipidemic rats with the high fat diet and aqueous extract of $A$. digitata may abate, revert or suppress the hyperlipidemic condition. 


\section{Material and methods}

\section{Material}

\section{Experimental Animals}

Male and female albino rats weighing between $80 \mathrm{~g}$ to $120 \mathrm{~g}$ were purchased from animal house of Biological Science Department, Bayero University, Kano. The animals were housed in well-ventilated cages in the animal house of Biological Science Department of Bayero University Kano. The rats had access to food and water. Principle of laboratory animal care (NIH Publication No. 85-23) (NIH, 1996) and ethical guidelines for investigation of experimental pain in conscious animals (Zimmermann, 1983) were observed during experimentation.

\section{Plant Material}

The fruits of Adansonia digitata was collected in Gosa community in Abuja Municipal Area Council and Gwargwada community in Kuje Area Council of the Federal Capital Territory (Abuja). The plant was identified and authenticated at the herbarium of the Department of Plant Biology, Bayero University Kano by a plant taxonomist, Bala'uddeen Said Adam on 31th October, 2014 with Accession Number BUK HAN0036.

\section{Methods}

\section{Preparation of Aqueous Fruit Pulp Extract $f$ A. digitata (Afpead)}

The collected fruit pulp was finely ground into powder form by using pestle and mortar. The seeds were separated from the pulp using a mesh. The fineness of the powdered pulp was achieved by sieving through a clean white muslin cloth allowing the fibres to be completely removed. The powder was stored in a clean air-tight plastic container at room temperature until use. Accurately $20 \mathrm{~g}$ of the powder was weighed into $100 \mathrm{ml}$ of distilled water to prepare a concentration of $200 \mathrm{mg} / \mathrm{ml}$ of Aqueous Fruit Pulp Extract of Adensonia digitata (AFPEAD) for administration to experimental animals in 24 hours.

\section{Administration of $A F P E A D$ to Animals}

The volume of the extract to administer to the experimental rats was determined based on the weight of the animals using the following relationship.

$$
\text { Volume }(\mathrm{ml})=\frac{\text { Dose }(\mathrm{mg} / \mathrm{kg}) \times \text { weight of rat }(\mathrm{kg})}{\text { Concentration of extract }(\mathrm{mg} / \mathrm{ml})}
$$




\section{Induction of Hyperlipidemia in Rats}

The high fat diet was formulated using the method of Vesselinvitch et al (1980) which is as follows: Pure cholesterol and palm oil were thoroughly mixed with the grower mash feed on a percentage ratio of 2:20:78 to formulate high lipid diet (HLD). The HLD was given to the animals for a period of three weeks to induce hyperlipidemic condition in the rats. The hyperlipidemic rats were maintained on the HLD throughout the study period.

\section{Experimental protocol}

The research involves the investigation of the effect of oral administration of aqueous extract of $A$. digitata on blood lipid profile in hyperlipidemic rats. A total of forty-two (42) rats were used, and grouped into seven (7) of six (6) rats each as follows:

Group I: normal control, not administered with AFPEAD

Group II: non- hyperlipidemic, administered with $2.5 \mathrm{~g} / \mathrm{Kg}$ of AFPEAD daily for two weeks

Group III: hyperlipidemic control, not treated with AFPEAD daily for two weeks

Group IV: hyperlipidemic rats treated with $1.25 \mathrm{~g} / \mathrm{Kg}$ of AFPEAD daily for two weeks

Group V: hyperlipidemic rats treated with $2.5 \mathrm{~g} / \mathrm{Kg}$ of AFPEAD daily for two weeks

Group VI: hyperlipidemic rats treated with $3.75 \mathrm{~g} / \mathrm{Kg}$ of AFPEAD daily for two weeks

Group VII: hyperlipidemic rats treated conventional anti hyperlipidemic drug (atorvastatin $10 \mathrm{mg} / \mathrm{Kg}$ ) daily for two weeks.

GIII - GVII were fed on high cholesterol diet throughout the experimentation. At the end of the first week, three animals from each group were selected randomly and sacrificed the remaining three animals continue to receive the treatment for another week and were sacrificed at the end of the second week.

\section{Estimation of Parameters}

Serum HDL and LDL-Cholesterol were assayed by the method of Friedward et al (1972), Triglycerides by the method of Trinder (1969) and Total Cholesterol by the method of Trinder (1969).

Artherogenic index was calculated using the formula as describe by Shinde et al (2013).

$$
\text { Atherogenic Index }(A I)=\frac{\text { Total Cholesterol }-H D L \text { Cholesterol }}{H D L \text { cholesterol }}
$$


Percentage increases or decreases were calculated using the relation:

Where;

$$
\%=\frac{\mathrm{Xs}-\mathrm{Cv}}{\mathrm{Cv}} \times 100
$$

$\mathrm{X}_{\mathrm{s}}=$ Sample value, $\mathrm{C}_{\mathrm{v}}=$ Reference Value (Normal control or high lipid diet (HLD) feed group).

\section{Statistical Analysis}

Results were expressed as mean \pm standard deviation and analysed using ANOVA followed by students $\mathrm{t}$ test in which $\mathrm{P}<0.001$ considered significant.

\section{Results and discussions}

Table1 presents the body weight in gram of dietary induced hyperlipidemic groups of rats treated with various concentrations of AFPEAD and a pharmaceutical anti - hyperlipidemic drug (atrivin) for seven (7) and fourteen (14) days. At end of three weeks inducement period (before treatment) there was no significant difference $(\mathrm{P}>0.001)$ except between GI and GII compared to GIII, GIV, GV, GVI and GVII, which may be attributed to the inducement of hyperlipidemia, hence becomes obesity prone. The trend was maintained in one and two week (s) of treatment of the hyperlipidemic condition with AFPEAD except for GIII that show a significantly higher $(\mathrm{P}<0.001)$ body weight compared to the remaining groups in both weeks of the treatment. The observed significant body weight gain in GIII in one and two weeks was not observed in treated hyperlipidemic groups (GIV - GVII) which may be attributed to anti hyperlipidemic activity of the AFPEAD in GIV, GV and GVI and artirivin drug in GVII. Figure 1 depicted percentage body weight gain for group of experimental rats. GI and GII show similar \% wt gain less than the hyperlipidemic groups. GIII show highest \% wt gain compared to treated hyperlipidemic groups (GIV, GV, GVI and GVII). Table 2 and 3 presents the effect of HLD and AFPEAD on indices of lipid profile (TCh, HDL-Ch, TG and LDL-Ch) in rats, in three weeks of feeding on the HLD and after one and two weeks of treatment of the hyperlipidemic rats with AFPEAD respectively. The result shows a significant increase $(\mathrm{P}<0.001)$ in TCh, LDL$\mathrm{Ch}, \mathrm{TG}$, artherogenic index (AI) and a significant decrease in HDL-Ch in hyperlipidemic negative control (G III) compared to normal control (G I). A significant decrease $(\mathrm{P}<0.001)$ in $\mathrm{TCh}, \mathrm{LDL}-\mathrm{Ch}$, TG and AI was observed in treated hyperlipidemic rats compared to GIII. Figure 2 and 3 present the percentage increase and decrease in lipid profile indices and artherogenic index; for HLD feed with neither extract nor drug (GIII) with respect to 
normal control (GI) and for test groups (GIV, GV, GVI and GVII) with respect to the negative control (GIII).

Table 1: Body weight of rats feed with high lipid diet (HLD) for three weeks and treated with extract of Adensonia digitata and atrovastatin drug for 7 and 14 days.

\begin{tabular}{|c|c|c|c|c|c|c|c|}
\hline $\begin{array}{c}\text { Group } \\
\text { Duration }\end{array}$ & $\begin{array}{c}\text { GI } \\
\text { contro } \\
\text { l }\end{array}$ & $\begin{array}{c}\text { GII } \\
2.5 \mathrm{~g} / \mathrm{K} \\
\mathrm{g} \\
\mathrm{AFPE} \\
\mathrm{AD}\end{array}$ & $\begin{array}{c}\text { GIII } \\
\text { Hyperli } \\
\text { pid. } \\
\text { Control }\end{array}$ & $\begin{array}{c}\text { GIV } \\
1.25 g / \\
\text { Kg } \\
\text { AFPE } \\
\text { AD }\end{array}$ & $\begin{array}{c}\text { GV } \\
2.5 \mathrm{~g} / \mathrm{K} \\
\mathrm{g} \\
\mathrm{AFPE} \\
\mathrm{AD} \\
\end{array}$ & $\begin{array}{c}\text { GVI } \\
3.75 g / \\
\text { Kg } \\
\text { AFPE } \\
\text { AD }\end{array}$ & $\begin{array}{c}\text { GVII } \\
\text { 10mg/ } \\
\text { Kg } \\
\text { atv }\end{array}$ \\
\hline 3week of & $\begin{array}{c}95.00^{\mathrm{a}} \\
\mathrm{b}, \mathrm{c} \\
\pm \\
1.67_{\mathrm{e}}\end{array}$ & 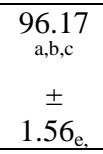 & $\begin{array}{c}107.33 \\
\text { a,b,c } \\
\pm \\
1.67_{\mathrm{f}}\end{array}$ & $\begin{array}{c}107.00 \\
\text { a,b,c } \\
\pm \\
1.33_{\mathrm{f}}\end{array}$ & $\begin{array}{c}106.83 \\
\text { a,b,c } \\
\pm \\
1.89_{\mathrm{f}}\end{array}$ & $\begin{array}{c}107.50 \\
\text { a,b,c } \\
\pm \\
2.33_{\mathrm{f}}\end{array}$ & $\begin{array}{c}106.33 \\
\text { a,b,c } \\
\pm \\
2.33_{\mathrm{f}} \\
\end{array}$ \\
\hline $\begin{array}{c}\text { One Week of extract } \\
\text { administration }\end{array}$ & $\begin{array}{c}119.67 \\
\text { a, c } \\
\pm \\
3.00_{\mathrm{e}} \\
\end{array}$ & $\begin{array}{c}121.67 \\
\mathrm{a}, \mathrm{c} \\
\pm \\
2.67 \mathrm{e} \\
\end{array}$ & $\begin{array}{c}154.00 \\
\mathrm{a}, \mathrm{c} \\
\pm \\
2.67 \\
\end{array}$ & $\begin{array}{c}139.17 \\
\mathrm{a}, \mathrm{c} \\
\pm \\
2.22_{\mathrm{u}} \\
\end{array}$ & $\begin{array}{c}139.17 \\
\mathrm{a}, \mathrm{c} \\
\pm \\
2.50_{\mathrm{u}} \\
\end{array}$ & $\begin{array}{c}141.17 \\
\mathrm{a}, \mathrm{c} \\
\pm \\
1.89_{\mathrm{u}} \\
\end{array}$ & $\begin{array}{c}138.67 \\
\mathrm{a}, \mathrm{c} \\
\pm \\
1.00_{\mathrm{u}} \\
\end{array}$ \\
\hline $\begin{array}{l}\text { Two weeks of extract } \\
\text { administration }\end{array}$ & $\begin{array}{c}148.00 \\
\mathrm{~b}, \mathrm{c} \\
\pm \\
1.33\end{array}$ & $\begin{array}{c}153.00 \\
\mathrm{~b}, \mathrm{c} \\
\pm \\
2.00 \\
\end{array}$ & $\begin{array}{c}201.33 \\
b, c \\
\pm \\
2.44 \\
\end{array}$ & $\begin{array}{c}189.33 \\
\text { b,c } \\
\pm \\
0.89_{w} \\
\end{array}$ & $\begin{array}{c}190.33 \\
\mathrm{~b}, \mathrm{c} \\
\pm \\
\pm .44_{\mathrm{w}} \\
\end{array}$ & $\begin{array}{c}190.00 \\
\text { b,c } \\
\pm \\
0.67_{\mathrm{w}} \\
\end{array}$ & $\begin{array}{c}186.00 \\
\text { b,c } \\
\pm \\
1.33 \\
\end{array}$ \\
\hline
\end{tabular}

Values in same column bearing similar super script differ significantly at $\mathrm{P}<0.001$, while value across the rows bearing same subscript are not significantly different $(\mathrm{P}>0.001)$.

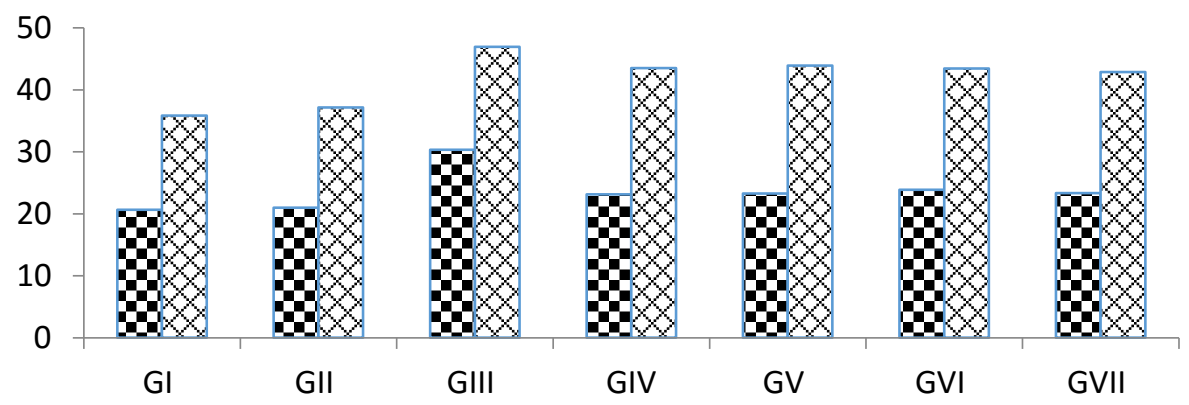

घt wk \% Body Wt. gain \2nd wk \% Body Wt. gain

Figure 1: percentage body weight gain for hyperlipidemic of rats treated for two weeks

Table 2: Serum lipid profile (mMol/L) and Artherogenic index (AI) of hyperlipidemic rats administered with AFPEAD for seven (7) days.

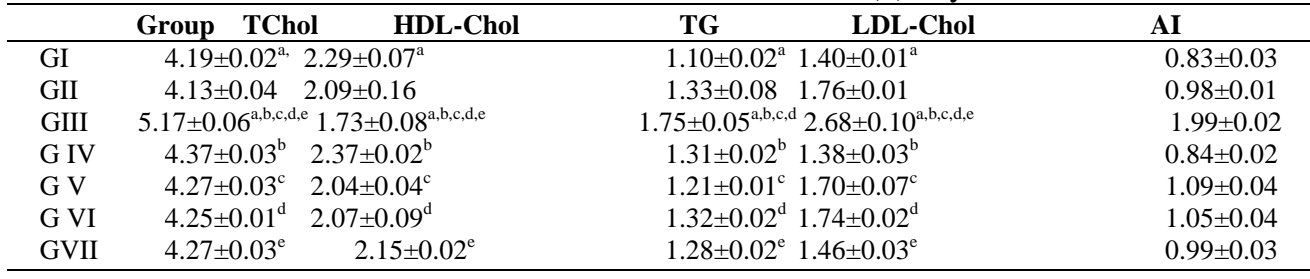




\section{Results are expressed as mean $\pm S D,(n=3)$. Values in the same column with similar superscripts are significantly different at $\mathbf{P}<0.05$.}

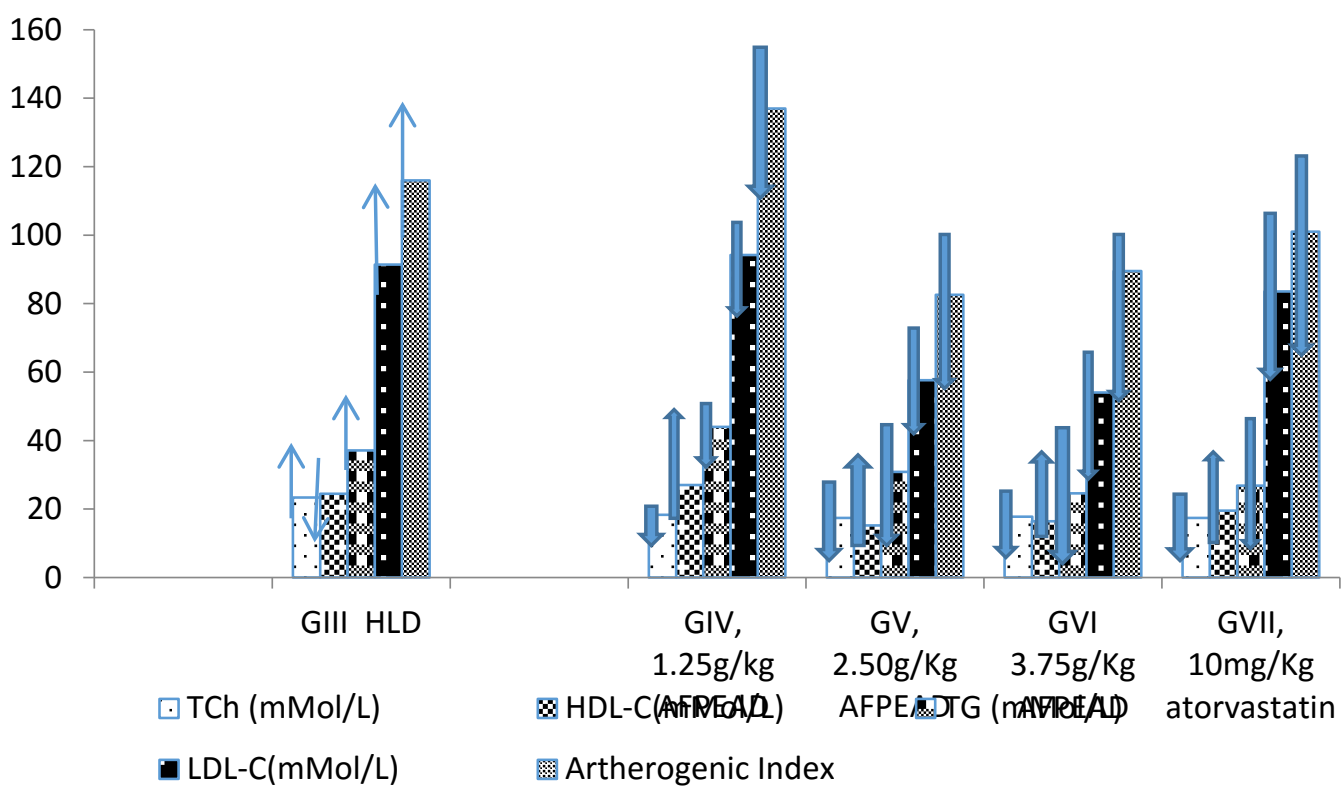

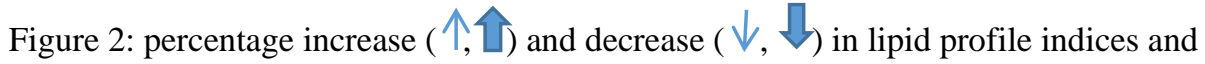
artherogenic index for

hyperlipidemic rats treated for one week $(\longrightarrow, \longrightarrow$ respectively compared to normal control and to high lipid diet

Table 3: lipid profile of hyperlipidemic rats administered with AFPEAD for fourteen (14) days

\begin{tabular}{cccccc}
\hline Groups & TC $(\mathrm{mMol} / \mathrm{L})$ & HDL-c $(\mathrm{mMol} / \mathrm{L})$ & TG $(\mathrm{mMol} / \mathrm{L})$ & LDL-c $(\mathrm{mMol} / \mathrm{L})$ & Artherogenic index \\
\hline & & & & & \\
G I & $4.17 \pm 0.06^{\mathrm{a}}$ & $1.75 \pm 0.02^{\mathrm{a}}$ & $1.13 \pm 0.01^{\mathrm{a}}$ & $1.80 \pm 0.04^{\mathrm{a}}$ & $1.38 \pm 0.03$ \\
G II & $4.28 \pm 0.03$ & $1.63 \pm 0.04$ & $1.23 \pm 0.07$ & $2.17 \pm 0.04$ & $1.68 \pm 0.05$ \\
G III & $7.15 \pm 0.02^{\mathrm{a}, \mathrm{b}, \mathrm{c}, \mathrm{d}}$ & $1.04 \pm 0.01^{\mathrm{a}, \mathrm{b}, \mathrm{c}, \mathrm{d}, \mathrm{e},}$ & $2.23 \pm 0.06^{\mathrm{a}, \mathrm{b}, \mathrm{c}, \mathrm{d}, \mathrm{e}}$ & $5.08 \pm 0.02^{\mathrm{a}, \mathrm{b}, \mathrm{c}, \mathrm{d}, \mathrm{e}}$ & $5.88 \pm 0.04$ \\
G IV & $4.28 \pm 0.03^{\mathrm{b}}$ & $1.85 \pm 0.04^{\mathrm{b}}$ & $1.18 \pm 0.03^{\mathrm{b}}$ & $2.85 \pm 0.09^{\mathrm{b}}$ & $1.31 \pm 0.04$ \\
G V & $5.07 \pm 0.06^{\mathrm{c}}$ & $1.70 \pm 0.06^{\mathrm{c}}$ & $1.12 \pm 0.01^{\mathrm{c}}$ & $2.86 \pm 0.07^{\mathrm{c}}$ & $1.98 \pm 0.07$ \\
G VI & $5.72 \pm 0.10^{\mathrm{d}}$ & $1.72 \pm 0.06^{\mathrm{d}}$ & $1.17 \pm 0.01^{\mathrm{d}}$ & $2.64 \pm 0.07^{\mathrm{d}}$ & $2.33 \pm 0.05$ \\
GVII & $4.83 \pm 0.11^{\mathrm{e}}$ & $1.84 \pm 0.08^{\mathrm{e}}$ & $1.27 \pm 0.03^{\mathrm{e}}$ & $2.53 \pm 0.06^{\mathrm{e}}$ & $1.630 \pm 0.06$
\end{tabular}

Results are expressed as mean \pm S.D $(n=3)$. Values in the same column with same superscripts are significantly different at $\mathrm{P}<0.05$. 


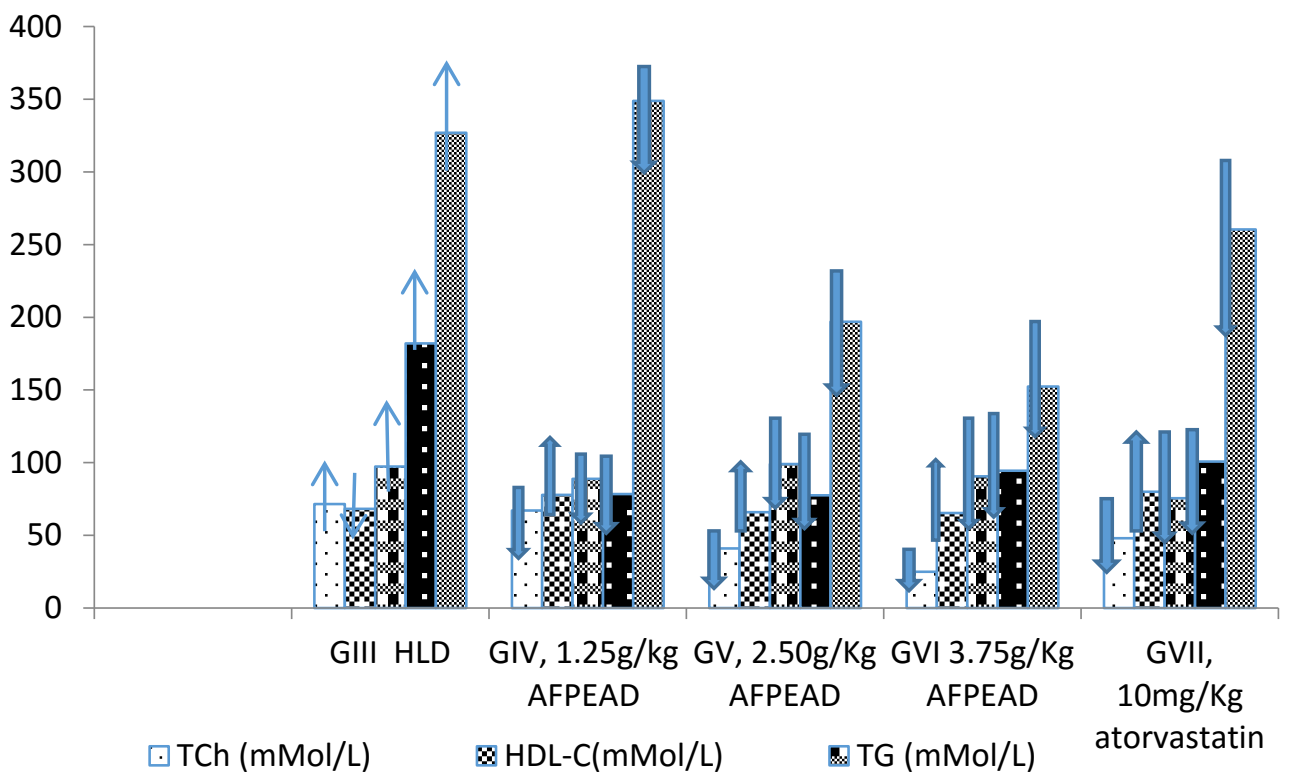

Figure 3: percentage increase ( $\uparrow$, 1 ) and decrease $(\checkmark, \downarrow)$ in lipid profile indices and artherogenic index for hyperlipidemic rats treated for two weeks $(\longrightarrow$, respectively compared to normal control and to high lipid diet )

\section{Discussions}

From table 1the significant difference $(\mathrm{P}<0.001)$ in body weight when compared GI and GII with groups (GIII - GVII) across the raw within three weeks on HLD shows that rats in GIII, GIV, GV, GVI and GVII are prone to obesity, induces by three weeks HLD feeds. The finding is in accordance with that of Vesselinvitch et al (1980); suggested that a dietary fats induced hyperlipidemic rat is obesity prone. Figure 1 may justify the statement of Vesselinvitch et al (1980), in which GIII indicated highest percentage weight gain compared to both normal control and treated hyperlipidemic groups. The reduced percentage body weight gain in GIV, GV and GVI could be associated with administration of the Adensonia digitata extract. It may infer that the extract reduces the accumulation of lipid in the rats. The inducement of hyperlipidaemia was evident by the differences in serum lipid profile indices between GI and GIII, in which the later show significantly higher lipid profile indices compared to the former due to the intake HLD. This echo well with statement of Austin (2007) who lamented that hyperlipidemic condition is presented with elevated serum total cholesterol, low density lipoprotein, very low density lipoprotein (LDL) cholesterol, reduced high density lipoprotein (HDL) or elevated hypertriglyceridemia. It is well documented that dyslipidemia, particularly hypercholesterolemia, induces tissue damage or provokes several human 
diseases (Ma et al., 2011). In a similar vein hypertriglyceridemia with concomitant hypercholesterolemia may be responsible for oxidative modification of LDL, protein glycation, glucose-autooxidation with excess production of free radicals and lipid peroxidation products (Yang et al., 2008), which represent major risk factors for ischemic heart diseases (Vandewoude, and Vandewoude, 1987; Carr et al., 2000; Howard et al., 2006). It may be true that reversal / reduction of dyslipidaemic condition in the hyperlipidemic rats models in this study prevent the provocation of the above mentioned diseases.

The significant higher body weight of GIII (Table 1) compared to the remaining groups in first and second weeks of the AFPEAD administration specifically in GIV, GV and GVI, may suggest or proved the acclaimed weight controlling ability of the plant among Hausa - Fulani of Northern Nigeria. The observed significant $(\mathrm{P}<0.001)$ decrease in the serum total cholesterol, triglycerides, LDL-cholesterol, and a significant increase in the HDL-cholesterol in hyperlipidemic rats treated with $1.25 \mathrm{~g} / \mathrm{kg}, 2.50 \mathrm{~g} / \mathrm{kg}$ and $3.75 \mathrm{~g} / \mathrm{kg}$ body weight of the extract (G IV, GV and GVI) and GVII treated with the drug atorvastatin (Atv) when to compared with the hyperlipidemic control (GIII) in both first and second week of treatment. This may suggest anti-serum hyperlipidemic activity of the plant which was comparable with the pharmaceutical agent (atorvastatin), the effect could be due to some phytochemical content of the plant pulp that may influences lipid metabolism thereby affect the serum lipid profile indices as does by the statins. The decreased serum cholesterol in the groups of rats treated with extract might be due to increased activity of enzyme LCAT (lecithin cholesterol acyltransferase) involved in esterification of cholesterol in the plasma. The significant decrease in serum triglycerides (TG) could be due to decreased accumulation of lipoprotein, associated with increased activity of lipoprotein lipase that involved in the uptake of TG rich lipoprotein by extra hepatic tissue. Other possible mechanisms by which AFPEAD regulates serum lipids profile may includes increasing LDL receptors of the hepatocytes or suppressing HMG-CoA reductase and thus lower the plasma and hepatic cholesterol concentrations (Lee et al., 1999).

It is imperative to note that statins a class of drugs used to lower cholesterol levels by inhibiting HMG-CoA reductase (Spindler et al., 2012), to limit production of mevalonate (Taylor et al., 2013). This is significant because most circulating cholesterol comes from endogenous synthesis rather than the diet. When the liver can no longer produce cholesterol, levels of cholesterol in the blood definitely falls (Endo, 1992). A number of statins include atorvastatin, fluvastatin, lovastatin, pitavastatin, pravastatin, rosuvastatin and simvastatin (Sweetman, 2009). It may be suggested that AFPEAD might be acting in the same mechanism for its hypolipedemic 
effect. This may be due to its contents and wide varieties of phytochemicals, including glycosides, tannins, quinic acid and a host of others.

\section{Conclusion}

Base on this study Adensonia digitata pulp could be used in controlling lipids accumulation hence body weight.

\section{References:}

Aliyu, B.S. (2006). Common ethnological plants of the semiarid regions West Africa. Triumph publishing company, Kano. ISBN 0-312-34863-0 Pp. 35.

Austin, M. A. (2007). Lipid Profile Automated assays for clinical analyzers to assess the risk of cardiovascular disease. Randox Laboratories Limited, 55 Diamond Road, Crumlin, County Antrim, BT29 4QY, United Kingdom. Endo, A. (1992). The discovery and development of HMG-CoA reductase inhibitors, J. Lipid Res. 33 (11): Pp. 1569-82

Friedwald, W.T., Levy,R.I and fredrickson, D.S. (1972). Estimation of the concentration of low density lipoprotein cholesterol in plasma, without use of preparative centrifuge. Clin chem.18: Pp. 499-502

Lee, S.H., Park, Y.B., Bae, K.H., Bok, SH., Kwon, Y.K., Lee. E.S and Choi, M.S (1999). "Cholesterol lowering activity of naringenin via inhibition of 3hydroxy-3-methylglutaryl coenzyme A reductase and acyl coenzyme A cholesterol acyltransferase in rats". Ann. Nutr. Metab. 43 (3): Pp. 173-80.

Ma, J.; Qiao, Z.; Xiang, X. (2011) Aqueous extract of Astragalus mongholicus ameliorates high cholesterol diet induced oxidative injury in experimental rats models. J. Med. Plants Res. 5, 855-858.

Mathers, C.D and Loncar, D. (2006). Projections of global mortality and burden of disease from 2002 to 2030. PLoS Med 3(11): Pp 442.

NIH (1996.). Guidelines for the care and use of laboratory animals. National Academic Press;

Nordmann, A.J., Suter-Zimmermann, K., Bucher, H.C., Shai, I., Tuttle, K.R., Estruch, R and Briel, M. (2011). "Meta-analysis comparing Mediterranean to low-fat diets for modification of cardiovascular risk factors." Am. J. Med. 124 (9): Pp 841-51.

Ross, R. (1999). "Atherosclerosis - an Inflammatory Disease". New England Journal of Medicine 340 (2): Pp 115-26

Sidibe, M. and Williams, J.T. (2002). Baobab - Adansonia digitata. International Centre for Underutilized Crops. Southampton, UK. ISBN 0854327762 Pp. 23-38

Spindler, S.R., Li, R., Dhahbi, J.M., Yamakawa, A., Mote, P., Bodmer, R., Ocorr, K., Williams, R.T., Wang, Y and Ablao, K.P. (2012). "Statin 
treatment increases lifespan and improves cardiac health in Drosophila by decreasing specific protein prenylation". PLoS ONE 7 (6): Pp. 395-81 Sweetman, S.C. (2009). "Cardiovascular drugs". Martindale: the complete drug reference (36th ed.). London: Pharmaceutical Press. ISBN 978-085369-840-1 Pp. 1155-434.

Taylor, F., Huffman, M.D., Macedo, A.F., Moore, T.H., Burke, M., Davey, S.G., Ward, K and Ebrahim, S. (2013). "Statins for the primary prevention of cardiovascular disease". Cochrane Database Syst Rev 1: Pp 56

Thompson, G.R. (2004). "Management of dyslipidaemia". Heart (British Cardiac Society) Pp 90

Torelli, J and Ryan, G (2005). Beyond cholesterol: 7 life-saving heart disease tests that your doctor may not give you (1st ed.). New York: St. Martin's Griffin. Pp. 91.

Trinder, P. (1969). Cholesterol enzymatic end point manual. Ann.clin.Biochem 6: Pp 24-25

Vesselinvitch, D., Wisseler, R.W., Schiffner, T.T. and Borenaztajn, I. (1980). The effect of various diet on atherogenesis in rhesus monkey. Atherosclerosis. 35: 187-207.

Vandewoude, M.F.; Vandewoude, M.G. (1987). Vitamin E status in normal population: The influence of age. J. Am. Coll. Nutr 6, 307-311.

World Health Organisation. (2005)."Definition, Diagnosis and Classification of Diabetes Mellitus and its Complications".

Yang, R.-L.; Shi, Y.-H.; Hao, G.; Li, W.; Le, G.-W. (2008) Increasing oxidative stress with Progressive hyperlipidemia in human: Relation between malondialdehyde and atherogenic index. J. Clin.Biochem. Nutr. 43, 154-158. Zimmermann, M. (1983) Ethical guidelines for investigation of experimental pain in conscious animals. Pain. 19:109-110. 